\title{
Supersonic Overland Without a Sonic Boom - Quantifying the Speed Advantage of Mach-Cutoff Flight
}

\author{
Bernd Liebhardt ${ }^{1}$ and Florian Linke ${ }^{2}$ \\ German Aerospace Center (DLR), Hamburg, Germany \\ Martin Knaack ${ }^{3}$ \\ Berlin Technical University, Germany
}

\begin{abstract}
When flying at low supersonic speeds, rising temperatures and convenient winds can deflect the sonic boom shock waves so that they do not reach the ground. This work presents a computation methodology that incorporates atmospheric sonic ray tracing, topography, and realistic 3-D atmospheres in order to optimize supersonic overland cruise with respect to speed. Flight missions are simulated on several suitable city pairs using numerous atmospheric conditions. Flight times and fuel consumption are compared to subsonic high-speed missions.
\end{abstract}

\section{Introduction}

$\mathrm{T}$

he sonic boom continues to be the main obstacle for civilian supersonic flight. As soon an airplane surpasses the speed of sound, it constantly emits shock waves that are perceived as loud bangs, even from large distances. This sonic boom is the reason for the factual ban of supersonic overland flight all over the world. Decades-long research, particularly promoted by the United States' National Aeronautics and Space Administration (NASA), has yielded remarkable progress in understanding, simulating, and mitigating the sonic boom with the eventual goal of unrestricted supersonic overland flight [1]. Yet, it still remains unclear when the technology will be mature enough to convince society and politics of lifting the ban.

In the meantime, there is an opportunity to realize supersonic flight over land using computer simulation technologies. It is well understood that for low supersonic speeds and for appropriate atmospheric conditions, the shock waves' propagation path will level off before reaching the ground. This principle of altitudinal "sonic boom cutoff" was described in detail half a century ago [2]. Plotkin, Matisheck, and Tracy [3] computed durations of coastto-coast flights over the United States and compared them to high-speed subsonic flights. Non-standard atmospheric data were used for the determination of a single averaged cutoff Mach number per mission, cruise took place on a fixed altitude above sea level, and climb as well as descent segments, respectively, were neglected. The present work takes a more detailed approach to Mach-cutoff assessment by simulating and optimizing entire flight missions, similarly aiming at the issue of time advantages for low-supersonic overland flight.

\footnotetext{
${ }^{1}$ Researcher; Air Transportation Systems, Blohmstrasse 20, 21079 D-Hamburg; Non-AIAA Member.

${ }^{2}$ Head of Department; Air Transportation Systems, Blohmstrasse 20, 21079 D-Hamburg; Non-AIAA Member.

${ }^{3}$ Research Associate; Berlin Technical University, Strasse des 17. Juni 136, 10623 D-Berlin; Non-AIAA Member.
}

American Institute of Aeronautics and Astronautics 


\section{Implementation of Mach-Cutoff Flight Simulation}

The capability of simulating and optimizing this so-called Mach-cutoff ${ }^{4}$ flight was implemented in DLR's proprietary SuperTraC (supersonic trajectory calculator) environment (also see [4, 5]). In its basic version, the code simulates subsonic, supersonic, and mixed missions from takeoff to touchdown, numerically solving the equations of motion and accounting for fuel consumption as well as airplane mass change, respectively. Subsonic cruise segments are flown on isobaric flight levels, as practiced in regular air traffic on instrumental flight rules, whereas supersonic cruise segments, usually starting above all subsonic traffic, are flown on a continuous shallow climb as the airplane's mass declines (see Figure 1).

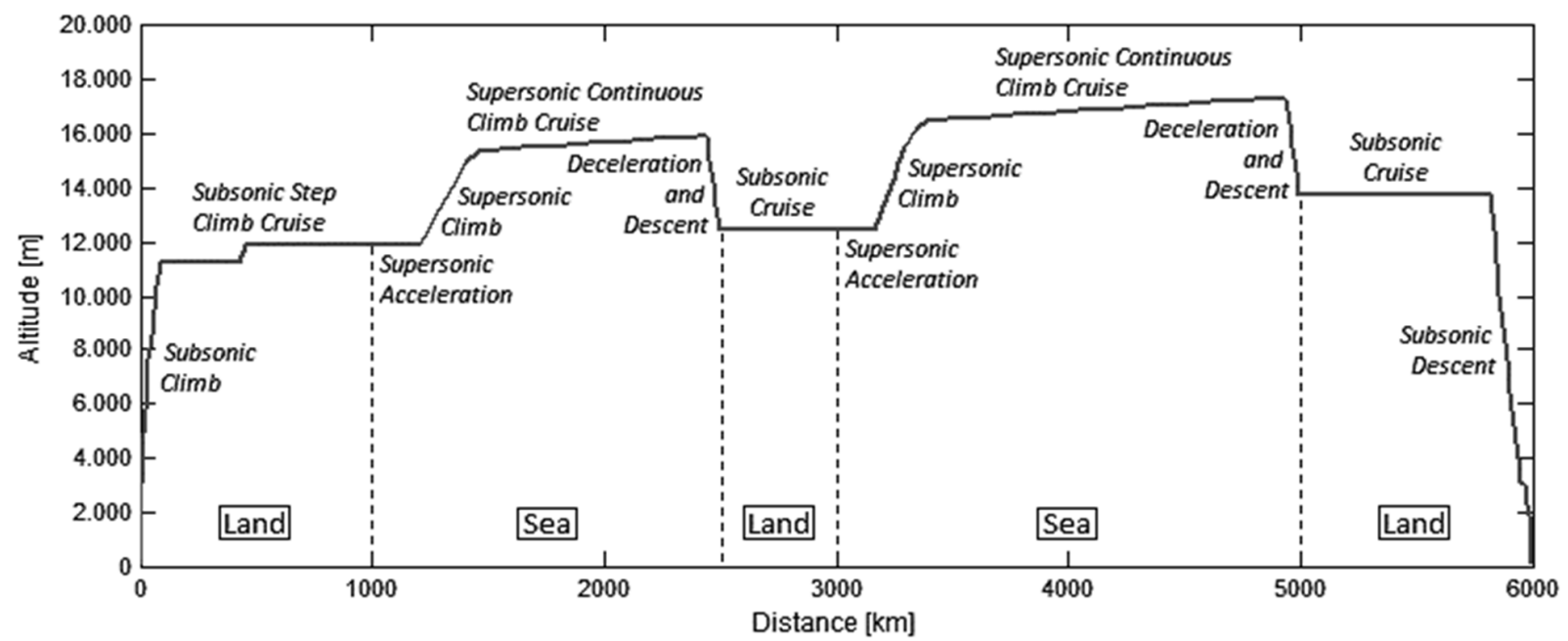

Figure 1. Generic SuperTraC mission trajectory.

SuperTraC uses realistic global 3-D atmospheric data ${ }^{5}$. They contain horizontal as well as vertical winds, they are discretized in steps of $0.75^{\circ}$ laterally and longitudinally, and they hold 60 altitude levels that top off at around 60 kilometers whereas the altitude increments increase going upward.

The updated SuperTraC additionally considers topography data from the publicly available Global Multiresolution Terrain Elevation Data set (GMTED20106), provided by the U.S. Geological Survey.

A sonic ray tracing methodology is used to determine locally flyable speeds. Ray tracing is a common concept in acoustics: A single point on a pressure wave front is tracked on its way through a medium (e.g. the atmosphere) by considering the gradual change in the medium's composition. For a sonic wave in air, the parameters governing its geometrical propagation are speed of sound and wind velocity. A ray's direction at the moment of emission depends on the aircraft's flight vector and on the flown Mach number. A comprehensive set of basic ray tracing equations is given by Onyeonwu [6]. The ray tracing algorithm implemented in SuperTraC additionally considers 3-D, nonstratified atmospheres as well as the Earth's curvature [5].

Finally, the SuperTraC simulation scheme for overland Mach-cutoff flight can be described in short as follows: An altitude buffer over ground is selected that the sonic boom is never allowed to transgress, namely the cutoff altitude. Cruise segments are flown on isobaric flight levels ${ }^{7}$. Test ray tracings are performed on the targeted flight level over a certain forward distance in adequately small distance steps in order to determine the cutoff Mach number. That is the maximum speed at which no ray (and its associated sonic boom) penetrates the cutoff altitude, whereas the latter is always added to the local topology. Cruise is done stepwise over said forward distances using the calculated cutoff Mach numbers. The described process is iterated and intertwined with adaptations of flight speed and flight level until the total cruise distance is reached.

\footnotetext{
${ }^{4}$ We call it Mach-cutoff flight because it is the Mach number that mainly governs the degree of cutoff, reflected in the altitude over ground that the sonic boom does not transgress.

${ }^{5}$ ERA-Interim data, provided by the European Center for Medium-range Weather Forecast (ECMWF).

${ }^{6}$ Available at www.usgs.gov/core-science-systems/eros/coastal-changes-and-impacts/gmted2010.

${ }^{7}$ It turned out that the considered aircraft designs' engine power rarely suffices for altitudes above $51,000 \mathrm{ft}$, which is the maximum certified flight level for present civilian aircraft, so that a climbing cruise will probably not be allowed.
}

American Institute of Aeronautics and Astronautics 
Flight missions from New York City to Los Angeles and back (flown by the HISAC-A supersonic business jet, see chapter III) are shown for illustration, using the atmosphere of January 1st, 2015, at 06:00 hours (UTC). Cutoff altitude was set to 5,000 feet over ground as a supposedly conservative safety buffer and for staying out of the atmospheric boundary layer where large eddies can strongly deflect the sonic boom's path. The respective trajectories can be seen to vary significantly. In the Western direction (see Figure 2), the flight reaches a top speed of Mach 1.25, and a time aloft of 3:50 hours is computed. The prevailing headwinds allow for the sonic boom to level off just above cutoff altitude. To the East (see Figure 3), the top speed is just Mach 1.10, but the flight time is 3:24 hours, 26 minutes shorter. For most of the distance, the sonic boom bottoms out at significantly higher altitudes, because by flying just slightly faster, the atmospheric conditions would irreversibly bend the critical propagation paths towards the ground.

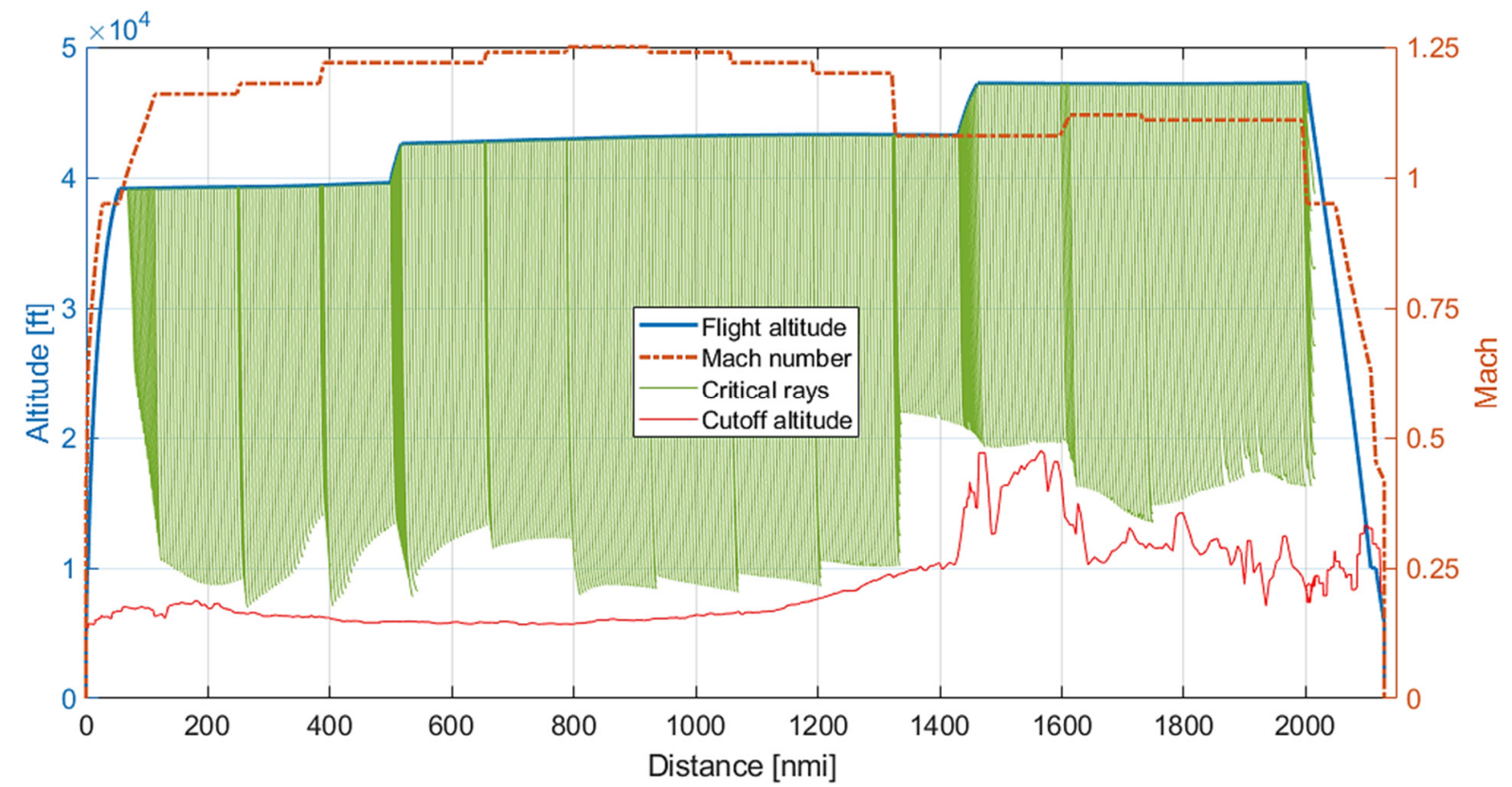

Figure 2. New York City - Los Angeles Mach-cutoff mission. Flight time: 3:50 hours. Headwinds prevailing.

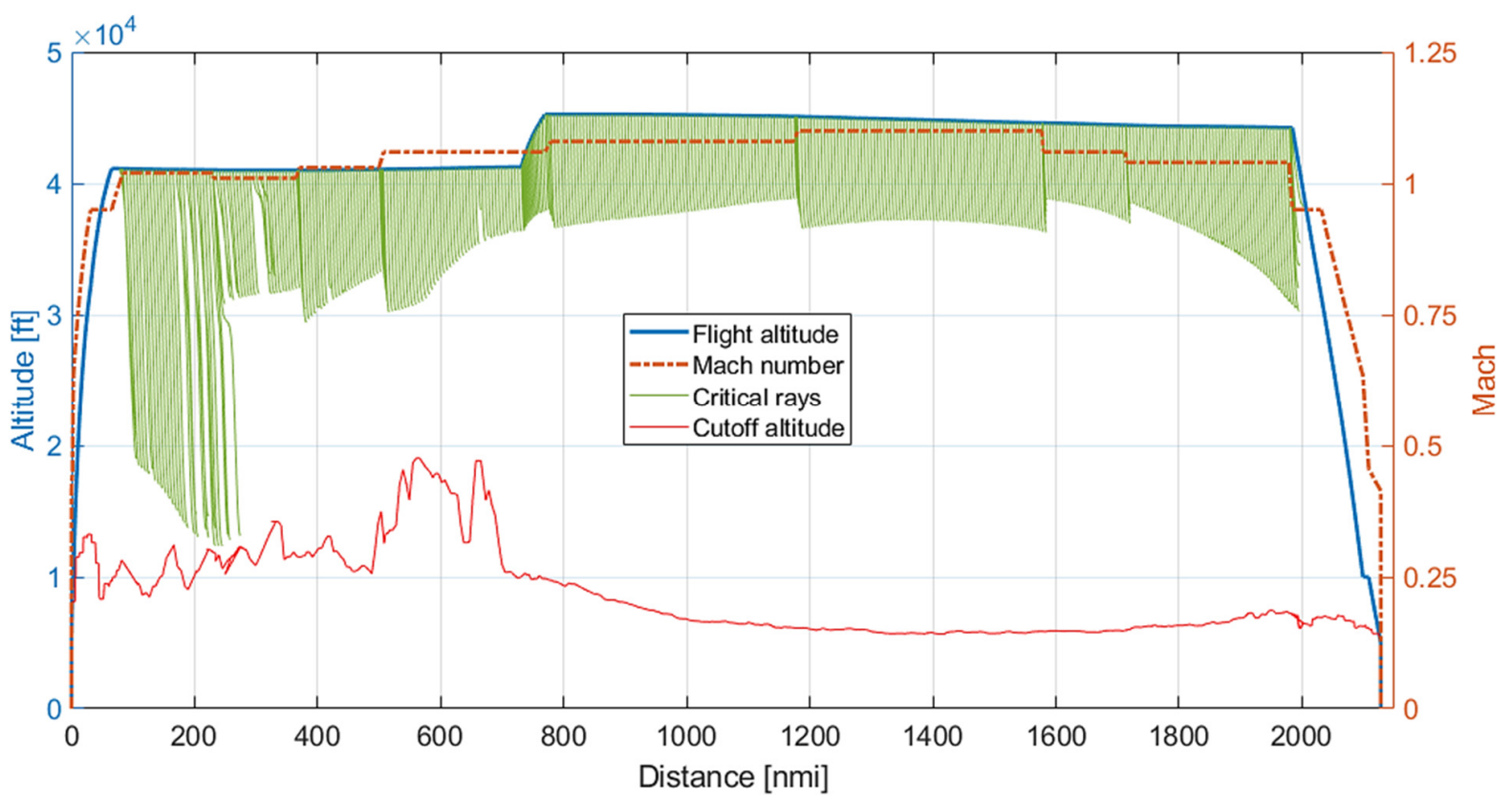

Figure 3. Los Angeles - New York City Mach-cutoff mission. Flight time: 3:24 hours. Tailwinds prevailing.

American Institute of Aeronautics and Astronautics 


\section{Design of Experiments}

Eight supposedly representative intra-continental, inter-metropolitan city pairs of considerable distance and thus, most relevant for Mach-cutoff flight missions, were chosen for assessment (see Table 1 and Figure 4).

\begin{tabular}{|r|l|c|}
\hline $\begin{array}{c}\text { City 1 } \\
\text { (State/ICAO airport code) }\end{array}$ & $\begin{array}{c}\text { City 2 } \\
\text { (State/ICAO airport code) }\end{array}$ & $\begin{array}{c}\text { Distance (direct/rerouted) } \\
\text { [nautical miles, } \text { nmi] }\end{array}$ \\
\hline New York City (NY/KTEB) & Los Angeles (CA/KVNY) & 2129 \\
\hline Seattle (WA/KBFI) & Melbourne (FL/KMLB) & 2259 \\
\hline Anchorage (AK/KANC) & Washington (DC/KIAD) & 2916 \\
\hline Boston (MA/KBED) & Vancouver (BC/CYVR) & 2170 \\
\hline Madrid (Spain/LETO) & Moscow (Russia/UUWW) & 1837 \\
\hline Beijing (China/ZBAA) & Moscow (Russia/UUWW) & 3150 \\
\hline Mumbai (India/VABB) & Moscow (Russia/UUWW) & $2716 / 2794$ \\
\hline Dubai (UAE/OMDB) & London (UK/EGLF) & $2982 / 3035$ \\
\hline
\end{tabular}

Table 1. Assessed city pairs and route distances.
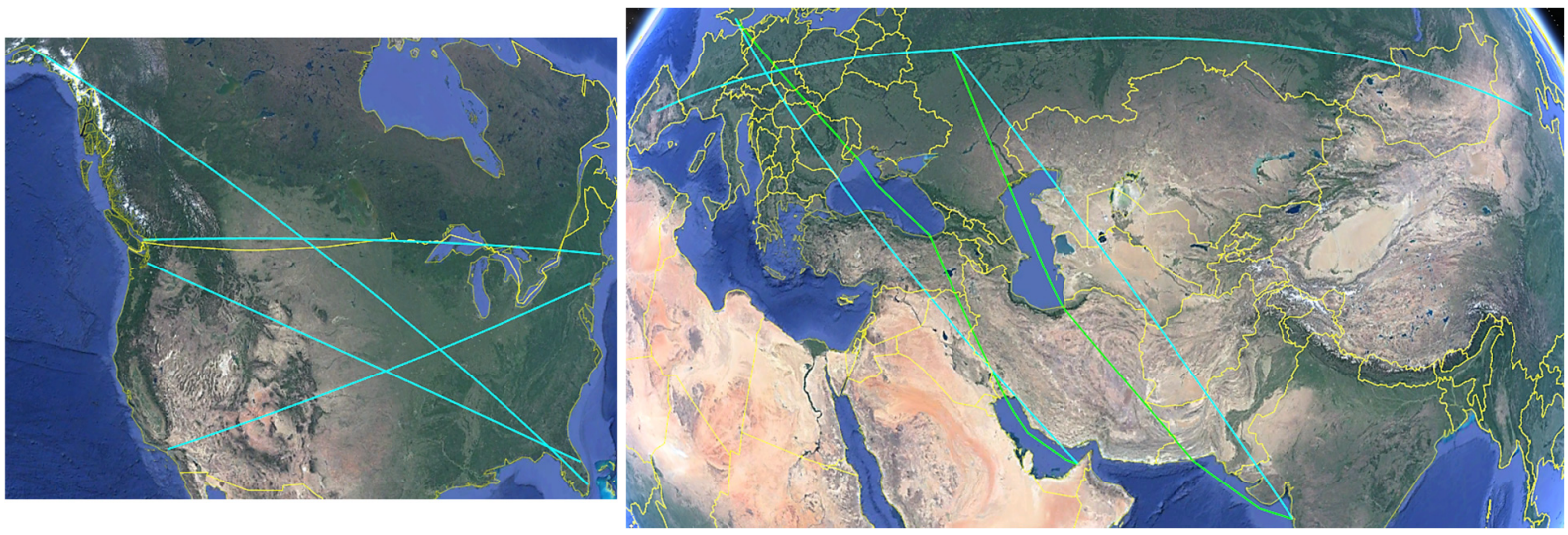

Figure 4. Assessed North American and Eurasian flight routes, resp. [Google Earth] (cyan: direct/great circle path; green: partially overwater path).

Two supersonic aircraft designs were considered: JAXA's S4 airliner (version 1.3.4 [7], see Figure 5) whose flight performance data were provided by JAXA, and the HISAC-A supersonic business jet leadingly designed by Dassault [8] (see Figure 6) whose flight performance data were re-engineered by DLR. Additionally, the Airbus A380 as a fastcruising airliner and the subsonic high-end business jet Dassault Falcon 7X were taken for comparison. The corresponding missions were simulated using DLR's Trajectory Calculation Module (TCM, [9]) with flight performance data originating from EUROCONTROL's Base of Aircraft Data (BADA) ${ }^{8}$.

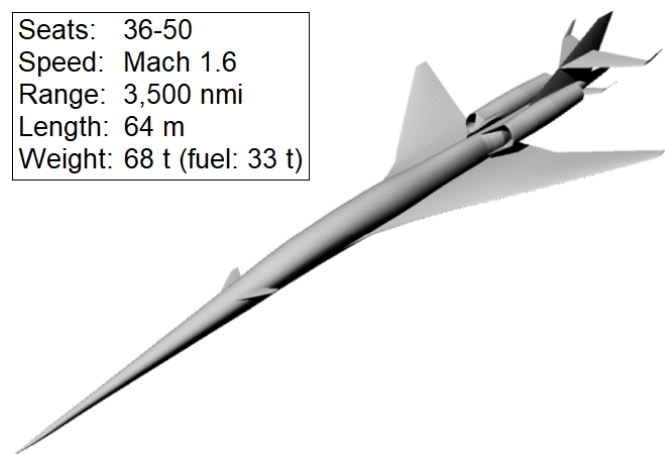

Figure 5. JAXA S4_1.3.4 supersonic airliner [7].

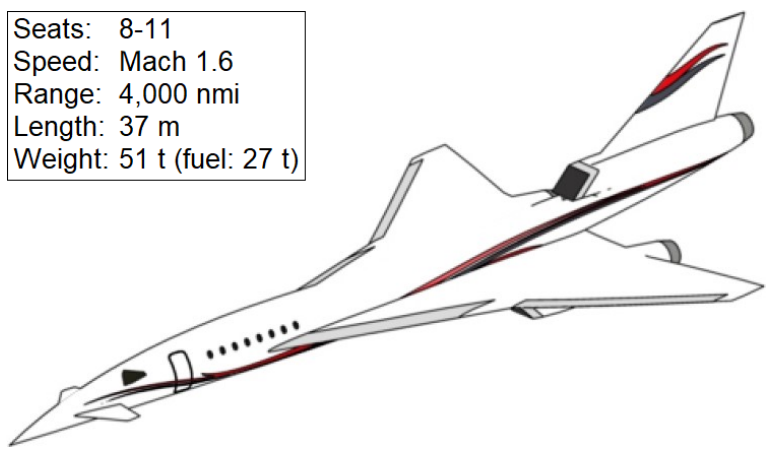

Figure 6. HISAC-A supersonic business jet [8].

${ }^{8}$ Available at www.eurocontrol.int/model/bada.

American Institute of Aeronautics and Astronautics 
On each route, simulations were performed in both directions for 365 different sets of atmospheric conditions (one for each day of the year 2015, time of day rotating). On the direct flight paths, the supersonic aircraft flew all-subsonic (Mach 0.95), Mach-cutoff, and all-supersonic (Mach 1.6) missions, and the subsonic aircraft flew subsonic missions at high speed (Falcon 7X: Mach 0.9; A380: Mach 0.85). On the rerouted flight paths, the supersonic aircraft flew a supersonic cruise (Mach 1.6) over water and either Mach cutoff or subsonic (Mach 0.95) over land.

In sum, 52,560 flight missions were simulated. A test matrix is shown in Table 2 as an overview.

\begin{tabular}{|c|c|c|c|c|c|c|c|}
\hline \multirow{2}{*}{ Aircraft type } & \multirow{2}{*}{$\begin{array}{l}\text { Supersonic } \\
\text { cruise } \\
\text { speed }\end{array}$} & \multirow{2}{*}{$\begin{array}{c}\text { Subsonic } \\
\text { cruise } \\
\text { speed }\end{array}$} & \multicolumn{3}{|c|}{$\begin{array}{c}\text { Missions on } \\
\text { direct flight paths }\end{array}$} & \multicolumn{2}{|c|}{$\begin{array}{l}\text { Missions on } \\
\text { rerouted flight paths }\end{array}$} \\
\hline & & & Subsonic & Mach-cutoff & Supersonic & $\begin{array}{l}\text { Supersonic/ } \\
\text { subsonic }\end{array}$ & $\begin{array}{l}\text { Supersonic/ } \\
\text { Mach-cutoff }\end{array}$ \\
\hline HISAC-A & M 1.6 & M 0.95 & $\mathrm{X}$ & $\mathrm{X}$ & $\mathrm{X}$ & $\mathrm{X}$ & $\mathrm{X}$ \\
\hline S4_1.3.4 & M 1.6 & M 0.95 & $X$ & $X$ & $X$ & $X$ & $X$ \\
\hline Falcon $7 \mathrm{X}$ & - & M 0.9 & $X$ & - & - & - & - \\
\hline A380 & - & M 0.85 & $X$ & - & - & - & - \\
\hline
\end{tabular}

Table 2. Test matrix.

\section{Results}

\section{A. Mach-Cutoff versus Subsonic Flight}

On the assessed routes, the mean time advantage of Mach-cutoff versus subsonic flight for the supersonic aircraft themselves is $12.5 \%-13 \%$ and 38 minutes, respectively. The maximum time saving was about 80 minutes whereas the minimum was about 10 minutes.

In case of supersonic aircraft flying Mach cutoff and the subsonic jets flying high-speed subsonic, the mean time advantage is $19.0-19.5 \%$ and 59-64 minutes, respectively. In extreme cases, 2:10 hours could be saved by the S4 versus the A380; the maximum advantage was 1:54 hours for the HISAC-A versus the Falcon 7X.

Fuel consumption increases by nearly 4 metric tons $(25 \%)$ and more than 2 metric tons (16\%) on average for the S4 and HISAC-A supersonic aircraft, respectively. Occasionally, it rises by nearly 34\% for the S4. Seven of the S4's missions from Beijing to Moscow could not be accomplished due to fuel insufficiency.

The Falcon $7 \mathrm{X}$ boasts considerably more range (nearly 6,000 nmi) and capacity (up to 16 passengers) compared to the HISAC-A jet. Yet, the HISAC-A averagely needs $67 \%$ more mission fuel using its subsonic cruise speed of Mach 0.95 (figure not listed below) and 109\% more when flying Mach cutoff.

The corresponding exact statistics are broken down in Table 3.

\begin{tabular}{|c|c|c|c|c|c|c|c|c|}
\hline \multirow{2}{*}{$\begin{array}{c}\text { Mach-cutoff vs. subsonic } \\
\text { cruise, direct routes only }\end{array}$} & \multicolumn{3}{|c|}{ Flight time savings } & \multicolumn{3}{c|}{ Additional fuel consumption } \\
\cline { 2 - 8 } & Mean & Max. & Min. & SD & Mean & Max. & Min. & SD \\
\hline \multirow{2}{*}{ S4_1.3.4 vs. S4_1.3.4 } & $12.5 \%$ & $21.1 \%$ & $4.1 \%$ & $3.1 \%$ & $24.9 \%$ & $33.8 \%$ & $11.1 \%$ & $3.6 \%$ \\
& $38 \mathrm{~min}$ & $81 \mathrm{~min}$ & $10 \mathrm{~min}$ & $13 \mathrm{~min}$ & $3.846 \mathrm{~kg}$ & $6.809 \mathrm{~kg}$ & $1.328 \mathrm{~kg}$ & $1.157 \mathrm{~kg}$ \\
\hline \multirow{2}{*}{ HISAC-A vs. HISAC-A } & $13.0 \%$ & $23.6 \%$ & $4.2 \%$ & $3,7 \%$ & $15.5 \%$ & $21.9 \%$ & $7.5 \%$ & $1.8 \%$ \\
& $38 \mathrm{~min}$ & $79 \mathrm{~min}$ & $9 \mathrm{~min}$ & $14 \mathrm{~min}$ & $2.124 \mathrm{~kg}$ & $4.109 \mathrm{~kg}$ & $730 \mathrm{~kg}$ & $625 \mathrm{~kg}$ \\
\hline \multirow{2}{*}{ S4_1.3.4 vs. A380 } & $19.5 \%$ & $34.5 \%$ & $6.9 \%$ & $4.5 \%$ & & & & \\
& $64 \mathrm{~min}$ & $130 \mathrm{~min}$ & $17 \mathrm{~min}$ & $22 \mathrm{~min}$ & & & & \\
\hline \multirow{2}{*}{ HISAC-A vs. Falcon 7X } & $19.0 \%$ & $28.1 \%$ & $9.1 \%$ & $3.4 \%$ & $108.6 \%$ & $144.3 \%$ & $67.6 \%$ & $12.9 \%$ \\
& $59 \mathrm{~min}$ & $114 \mathrm{~min}$ & $21 \mathrm{~min}$ & $16 \mathrm{~min}$ & $10.595 \mathrm{~kg}$ & $16.513 \mathrm{~kg}$ & $5.730 \mathrm{~kg}$ & $2.579 \mathrm{~kg}$ \\
\hline
\end{tabular}

Table 3. Flight time savings and additional fuel consumption, Mach-cutoff vs. subsonic, direct routes.

The absolute time advantage of Mach-cutoff flight increases with distance, as could be expected, whereas the relative advantage exhibits no obvious change by tendency.

Further, a considerable spread between eastward and westward missions can be observed. Westbound flight yields larger time savings for Mach cutoff due to the smaller relative impact of headwinds (79-121 minutes maximum advantage westward vs. 54-87 minutes maximum advantage eastward, respective to airplane pairings); see Table 4.

An exemplary set of boxplots displaying time and fuel, relative and absolute difference distributions for the HISAC-A Mach-cutoff vs. subsonic missions can be found in Appendix A.

American Institute of Aeronautics and Astronautics 


\begin{tabular}{|c|c|c|c|c|c|c|c|c|}
\hline \multirow{2}{*}{$\begin{array}{c}\text { Mach-cutoff vs. subsonic } \\
\text { cruise, direct routes only }\end{array}$} & \multicolumn{3}{|c|}{ Flight time savings, eastwards } & \multicolumn{3}{c|}{ Flight time savings, westwards } \\
\cline { 2 - 8 } & Mean & Max. & Min. & SD & Mean & Max. & Min. & SD \\
\hline \multirow{2}{*}{ S4_1.3.4 vs. S4_1.3.4 } & $10.2 \%$ & $17.1 \%$ & $4.1 \%$ & $2.2 \%$ & $14.9 \%$ & $21.1 \%$ & $8.7 \%$ & $2.0 \%$ \\
& $29 \mathrm{~min}$ & $58 \mathrm{~min}$ & $10 \mathrm{~min}$ & $8 \mathrm{~min}$ & $47 \mathrm{~min}$ & $81 \mathrm{~min}$ & $20 \mathrm{~min}$ & $11 \mathrm{~min}$ \\
\hline \multirow{2}{*}{ HISAC-A vs. HISAC-A } & $10.0 \%$ & $18.9 \%$ & $4.2 \%$ & $2.1 \%$ & $15.9 \%$ & $23.6 \%$ & $9.1 \%$ & $2.3 \%$ \\
& $27 \mathrm{~min}$ & $54 \mathrm{~min}$ & $9 \mathrm{~min}$ & $8 \mathrm{~min}$ & $49 \mathrm{~min}$ & $79 \mathrm{~min}$ & $20 \mathrm{~min}$ & $11 \mathrm{~min}$ \\
\hline \multirow{2}{*}{ S4_1.3.4 vs. A380 } & $15.9 \%$ & $26.1 \%$ & $6.9 \%$ & $2.6 \%$ & $23.2 \%$ & $34.5 \%$ & $13.1 \%$ & $2.5 \%$ \\
& $49 \mathrm{~min}$ & $89 \mathrm{~min}$ & $17 \mathrm{~min}$ & $14 \mathrm{~min}$ & $80 \mathrm{~min}$ & $130 \mathrm{~min}$ & $28 \mathrm{~min}$ & $18 \mathrm{~min}$ \\
\hline \multirow{2}{*}{ HISAC-A vs. Falcon 7X } & $16.7 \%$ & $24.1 \%$ & $9.1 \%$ & $2.7 \%$ & $21.4 \%$ & $28.1 \%$ & $14.5 \%$ & $2.1 \%$ \\
& $48 \mathrm{~min}$ & $78 \mathrm{~min}$ & $21 \mathrm{~min}$ & $9 \mathrm{~min}$ & $70 \mathrm{~min}$ & $114 \mathrm{~min}$ & $35 \mathrm{~min}$ & $14 \mathrm{~min}$ \\
\hline
\end{tabular}

Table 4. Flight time savings of eastward and westward missions, Mach-cutoff vs. subsonic, direct routes.

\section{B. General Distribution of Cutoff Mach Numbers}

Figure 7 displays the distribution of all cutoff Mach numbers flown on the simulated missions. ${ }^{9}$ The mean value is 1.111 for the HISAC-A and 1.115 for the S4. The maximum encountered cutoff Mach number was 1.37.

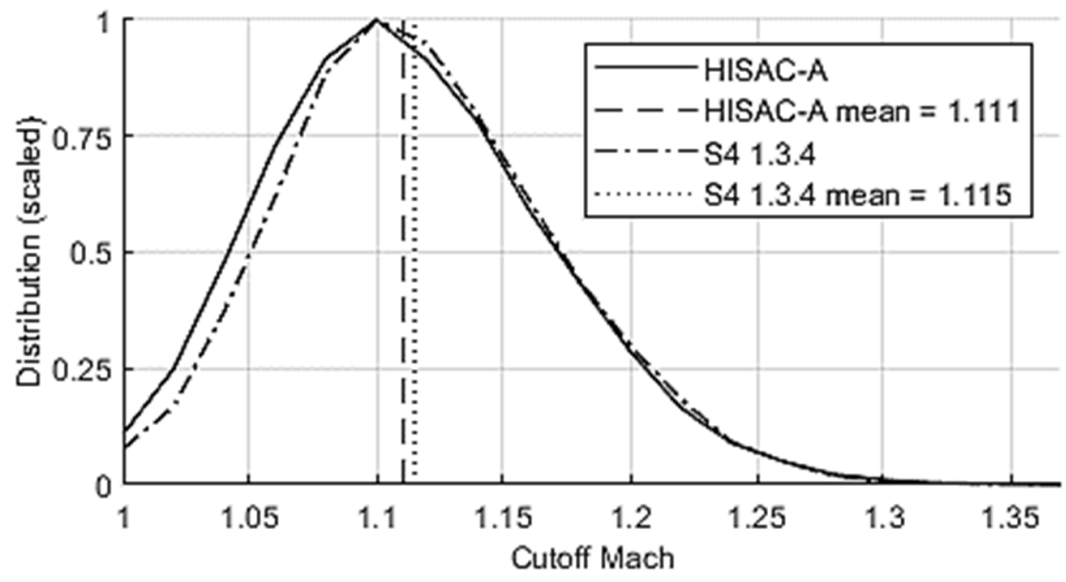

Figure 7. Distribution of cutoff Mach numbers flown in cruise.

Due to the route-specific nature of the found cutoff Mach numbers, an additional Monte Carlo experiment was conducted to analyze cutoff Mach numbers more generally. 5,000 ft were again taken as the basic cutoff altitude. For each of the 365 atmospheres, 1000 geographic locations over land were picked at random ${ }^{10}$. At each location, eastward as well as westward flight was considered. Since a bandwidth of cruise flight levels between 340 and 510 was retrieved from the simulated Mach-cutoff flights, this experiment employed appropriate flight levels from the ones that air traffic management regularly assigns: 330, 350, 370, 390, 410, 450, 490 eastwards and 340, 360, 380, 400, 430, 470, 510 westwards. All in all, 5,110,000 cutoff Mach numbers were computed.

The experiment reveals the possibility of even higher cutoff Mach numbers, namely up to 1.44 in extreme cases; see Figure 8. Due to the Earth's prevailing wind direction, the mean values on eastward flight $(1.060-1,105$, respective to flight level) are generally lower than going westwards (1.141-1.173). Cutoff Mach numbers increase with altitude by tendency. However, examples abound where the maximum cutoff Mach number does not coincide with the highest flight level; see Figure 9. This occurred in about $45 \%$ of eastward and $71 \%$ of westward cases and is probably due to wind velocities generally reaching their maximum in the upper stratosphere and decreasing again going upward.

Further, the spectrum of cutoff Mach numbers varies with geographic latitude and with the season (see Appendix B). The weather in January distorts the spectrum more than the weather in July, even in southern latitudes, which is somewhat surprising. Tropical latitudes generally allow for higher cutoff Mach numbers than going toward the poles.

\footnotetext{
${ }^{9}$ The employed resolution for Cutoff Mach numbers was 0.01 Mach, with a security buffer of 0.005 Mach minimum. Roughly $3 \cdot 10^{6}$ Cutoff Mach numbers were determined for both supersonic aircraft.

${ }^{10}$ Latitudes above $75^{\circ} \mathrm{N}$ and below $55^{\circ} \mathrm{S}$ were excluded because no plausible reason could be imagined for Machcutoff flight in the Arctic or the Antarctic.
}

American Institute of Aeronautics and Astronautics 


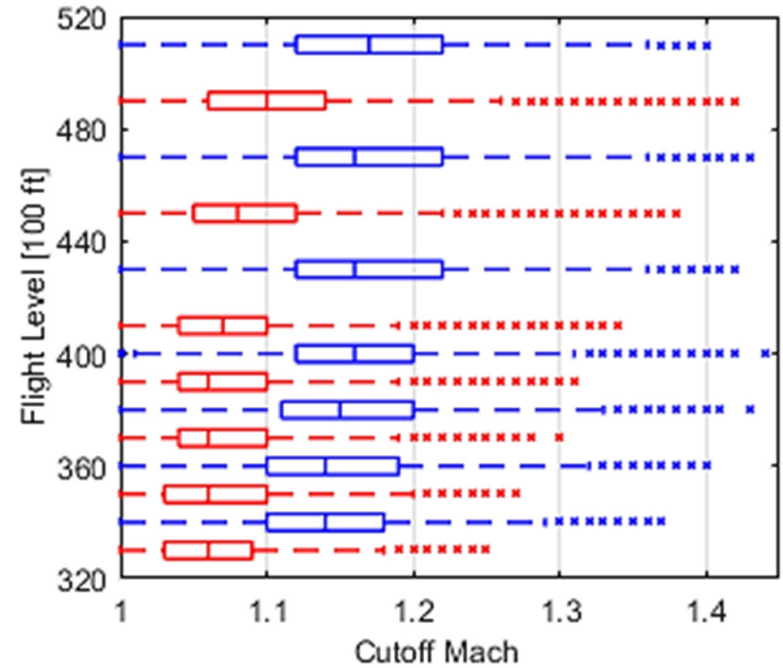

Figure 8. General distribution of cutoff Mach numbers (red: eastwards; blue: westwards).

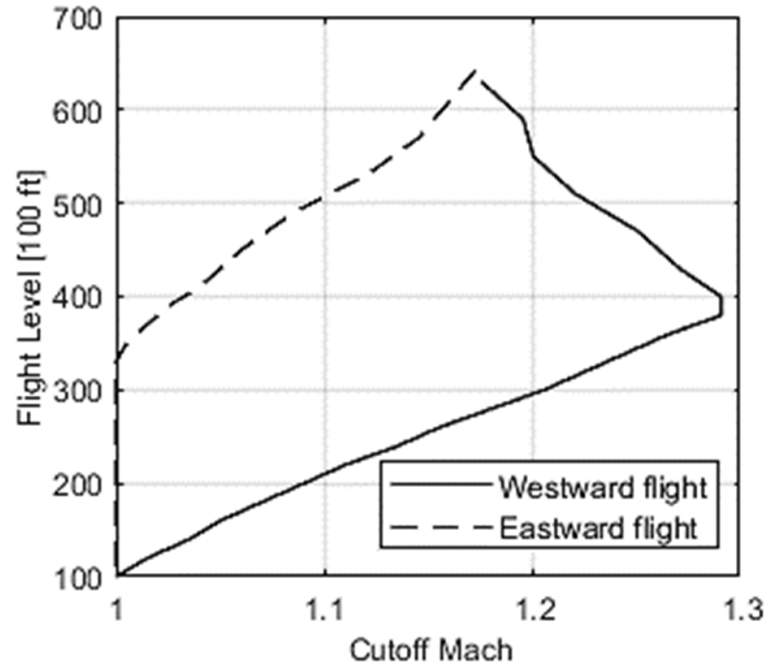

Figure 9. Sample of cutoff Mach over altitude ${ }^{11}$ (Atmosphere of 2015-01-01-00, $3^{\circ} \mathrm{N} 98^{\circ} \mathrm{W}$ ).

\section{Supersonic Flight Modes}

The supersonic missions were simulated to gain additional reference figures, but also for code-demonstration and code-testing purposes. By this, the mixed-speed mission simulation in particular was made more robust, e.g. against challenging atmospheric conditions that strongly shift supersonic acceleration and deceleration onsets, respectively.

The city pairs of Mumbai-Moscow and Dubai-London were chosen because of their possibility to fly noninsignificant distances over water at high speed with only slight detours. Therefore, it was not immediately clear which flight mode would be the fastest. It eventually turned out that for these specific cases, direct Mach-cutoff flight was generally slightly faster than mixed subsonic/supersonic flight, and mixed Mach-cutoff/supersonic flight was again slightly faster than Mach-cutoff flight (see Appendix C, bottom figures).

Appendix C displays a juxtaposition of flight times of the S4 aircraft over a calendar year's course on all routes for all cruise modes.

\section{Discussion}

\section{A. Model complexity}

The applied supersonic trajectory calculation model SuperTraC has grown highly complex. It uses extensive data sources (e.g. aircraft performance parameters, atmospheric data in 3-D, global topography), it links separate sophisticated models (e.g., mission segmentation, flight performance calculation, atmospheric data interpolation, sonic ray tracing), and it processes a high number of variables. A major purpose of this work is to demonstrate the successful integration of the governing parameters for the simulation and optimization of Mach-cutoff overland missions.

It is planned to increase the complexity of SuperTraC even further to the point of optimizing supersonic missions for cutting off sonic booms not just vertically, but also laterally, namely on high-speed overwater segments where the sonic boom reaches the water surface. First steps in that direction have been taken in [4, 5]; the final goal is implementing sonic boom signature propagation and loudness calculation codes, respectively, to determine and optimize the position of the acoustic sonic boom carpet on water.

\section{B. Comparison of results with Plotkin [3]}

Plotkin et al. [3] reported speed improvements of 27-47\% for Mach-cutoff flight relative to subsonic high-speed flight, which happened at Mach 0.85 in their case. Nowadays, high-end business jets like the Gulfstream G650 or the Bombardier 7000 allegedly cruise at Mach 0.9 routinely. The speed improvements measured in the present analysis were $18-61 \%$ (S4 vs. A380 at Mach 0.85) and 11-52\% (HISAC-A vs. Falcon 7X at Mach 0.9).

${ }^{11}$ The altitude spectrum was augmented for this case.

American Institute of Aeronautics and Astronautics 
Further, Plotkin stated that coast-to-coast flights across the United States would shorten flight times by an hour or more. On the coast-to-coast city pairs of this assessment (NYC-LAX, SEA-MLB, BOS-YVR), the mission times saved by the HISAC-A jet versus the Falcon 7X came out as 43-90 min westward and as 21-69 min eastward. For the S4 - A380 comparison, the computed mission time savings are 46-124 min and 17-65 min, respectively.

Thus, it can be concluded that whereas Plotkin's assessment was less detailed, their figures sit fairly well within the bandwidth of the present study's results.

\section{Cruise speed optimization}

As shown above, the highest altitudes often do not coincide with the highest cutoff Mach numbers. Presently, the algorithm always chooses the highest possible flight level with respect to aircraft performance, which maximizes flight range. An alternative could be choosing the flight level with the highest cutoff Mach number, which would slightly decrease flight durations further. However, this would probably infer changing altitudes more frequently as well as encountering more traffic on lower flight levels. It appears doubtful whether the air traffic authorities, who would already need to accommodate the supersonic aircraft's higher speed, would approve such procedures.

Another parameter to optimize is the cycle length of speed adaptation. In this study, a new cutoff Mach number was adopted every 250 kilometers of flight distance. A decrease of the cycle length would lead to faster missions, because a cycle always takes the lowest of the encountered cutoff Mach numbers. However, there is a lower limit due to the distance required for speed adaptation, in particular for accelerations. Also, frequent deceleration, happening faster than acceleration, might reduce passenger comfort (which analogously applies to flight level changes).

\section{Limitations of results}

- JAXA's S4 aircraft is designed for low-boom, high-cruise-speed supersonic overland flight. Therefore, the present Mach-cutoff application doesn't actually apply to its intended operations. The aircraft was taken for its available, high-detail flight performance data. It is known that low-boom aircraft, like this one, trade some aerodynamic efficiency for favorable sonic boom signatures. Thus, aircraft without low-boom characteristics would actually consume somewhat less fuel on Mach-cutoff flights than the S4.

- The present assessment confined itself to routes of distances significantly below the alleged range of future supersonic aircraft. Longer routes would naturally result in higher time savings. However, the reasonability of the chosen routes is demonstrated by the fact that Beijing-Moscow flights could not be absolved using Mach cutoff in seven distinct cases due to strong headwinds and insufficient range, respectively.

- Only geometrical propagation was used to restrain the sonic boom from reaching the ground. The methodology could be improved by including acoustic propagation of sonic boom signatures. This would help exclude longreaching rays that would geometrically reach the surface, but would not be heard because their sound has already dissolved in background noise.

\section{E. Real-world application}

Several issues exist with realizing Mach-cutoff flight modes:

- Regulations: For legal Mach-cutoff flight, air traffic regulations would have to be amended at least in the United States and in Canada because they entirely prohibit civilian flight at supersonic Mach numbers ${ }^{12}$. The International Civil Aviation Organization (ICAO), whose resolutions are adopted by many nations' authorities, allows Mach cutoff in principle because it only asks for "no unacceptable situation for the public" to be caused by sonic booms ${ }^{13}$.

- Transonic aerodynamics: Mach-cutoff flight would happen in the transonic realm where the air flow around aircraft exhibits areas of oscillating shock waves that cause flow separation. This phenomenon is known to put strain on neighboring structures. If Mach cutoff flight is desired, these special loads have to be considered in aircraft design.

- Short-term weather forecasting: Randomly assessing trajectories of same routes and same aircraft with atmospheric data 6 hours apart (which was the minimum increment at hand), differences in cutoff Mach numbers of at least $0.05 \mathrm{Mach}$ at the same positions were observed (whereas the chosen safety buffer in simulations was just 0.005 Mach). This indicates that shorter-term atmospheric variability probably has a significant impact on sonic boom propagation. If Mach-cutoff overland flight shall become operative, particularly accurate weather forecasts will be required. It further appears plausible that cruise speeds cannot be planned beforehand and will need recurrent updating during missions.

\footnotetext{
${ }^{12}$ USA: 14 CFR $\$ 91.817$; Canada: SOR/96-433 $\$ 602.33$

${ }^{13}$ See https://www.icao.int/environmental-protection/documents/ICAO\%20Environmental\%20Report\%202016.pdf.
} 8 
- ATM integration: When flying at Mach-cutoff speeds, the assessed supersonic aircraft will use the same flight levels as regular subsonic traffic. Air traffic management would have to integrate them by providing greater clearances between aircraft on airways, and new routines might be needed. Mach-cutoff flight modes would probably reduce air traffic capacities and might therefore be precluded in situations of high traffic.

- Evanescent waves: When a sonic boom shock wave levels off, there is still a perceptible rumble below that altitude, whereas its loudness decreases exponentially going downward. Valuable studies have been conducted by NASA to measure the height of that "shadow zone" in which sonic booms can still be heard [10]. However, extensive flight testing is probably still needed for setting up parametric formulae that quantify safe altitude buffers and appropriate cutoff altitudes, respectively, for civilian Mach-cutoff flight.

\section{F. Synthesis}

Mach-cutoff flight appears to be technically possible to operate in theory, whereas considerable testing will be required in several respects, as discussed above. It brings modest time savings and infers considerable fuel overconsumption. Therefore, it can be imagined rather for private flight where the speed advantage can be exploited for subjective reasons than for airline service where cost efficiency is paramount.

\section{Conclusion}

This work presented a methodology to simulate and optimize flight missions that employ varying low-supersonic cruise speeds which preclude the sonic boom from reaching the ground. This flight mode is called Mach cutoff. The complex computation algorithm utilizes aircraft performance data, non-standard 3-D atmospheres, topography, and coast lines as inputs. It applies a sonic ray tracing routine to track the sonic boom's atmospheric propagation and to maximize the flight speed such that the boom satisfies a certain buffer between its level-off altitude and the ground. The methodology was demonstrated by simulating Mach-cutoff flight missions on eight market-relevant city pairs of adequate distance in numerous different atmospheric conditions. Compared to subsonic missions at Mach 0.95, the flight time savings were 38 minutes on average $(9-81 \mathrm{~min})$ and highly subject to direction (westward/headwinds: 48 min; eastward: $28 \mathrm{~min}$ ). Fuel consumption increased by $8-34 \%$. Compared to contemporary subsonic counterpart aircraft, time savings were higher (17-130 min), but fuel consumption against a model more capable regarding seat capacity and range was elevated by more than $100 \%$ on average. A major purpose of this work is to demonstrate the complex methodology's functionality. It is part of a greater effort towards automated design and optimization of supersonic, rule-compliant flight routes over water where the sonic boom reaches neither the ground nor populated shores. 


\section{Appendix}

A. Comparison of mission times and fuels for Mach-cutoff vs. subsonic flight, HISAC-A aircraft

Boxes, left to right: Madrid - Moscow, New York - Los Angeles, Boston - Vancouver, Seattle - Melbourne, Mumbai-Moscow, Anchorage-Washington, Dubai-London, Beijing-Moscow.

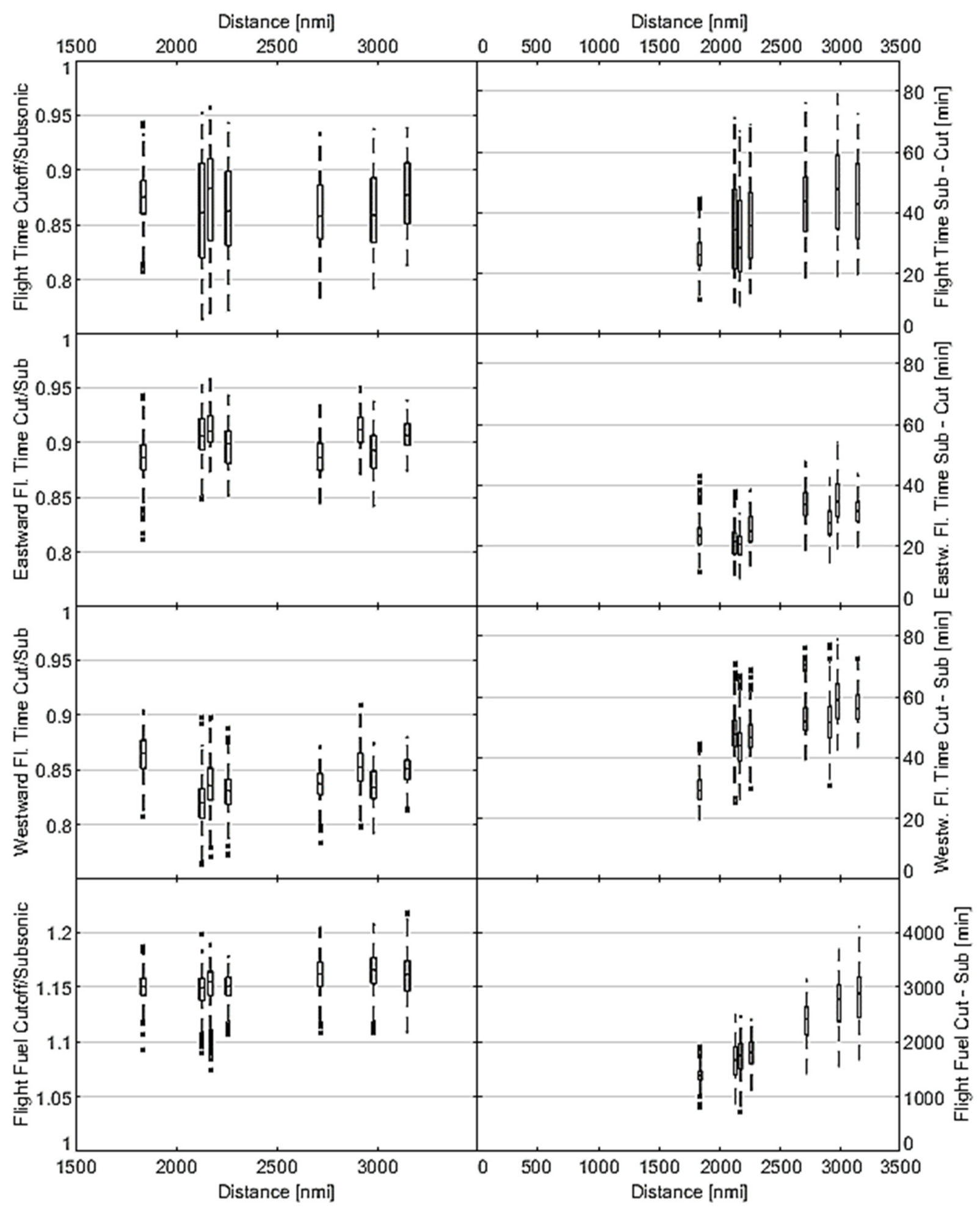

10

American Institute of Aeronautics and Astronautics 
B. Cutoff Mach Numbers Over Latitudes w.r.t. Flight Level, Time of Year, and Flight Direction

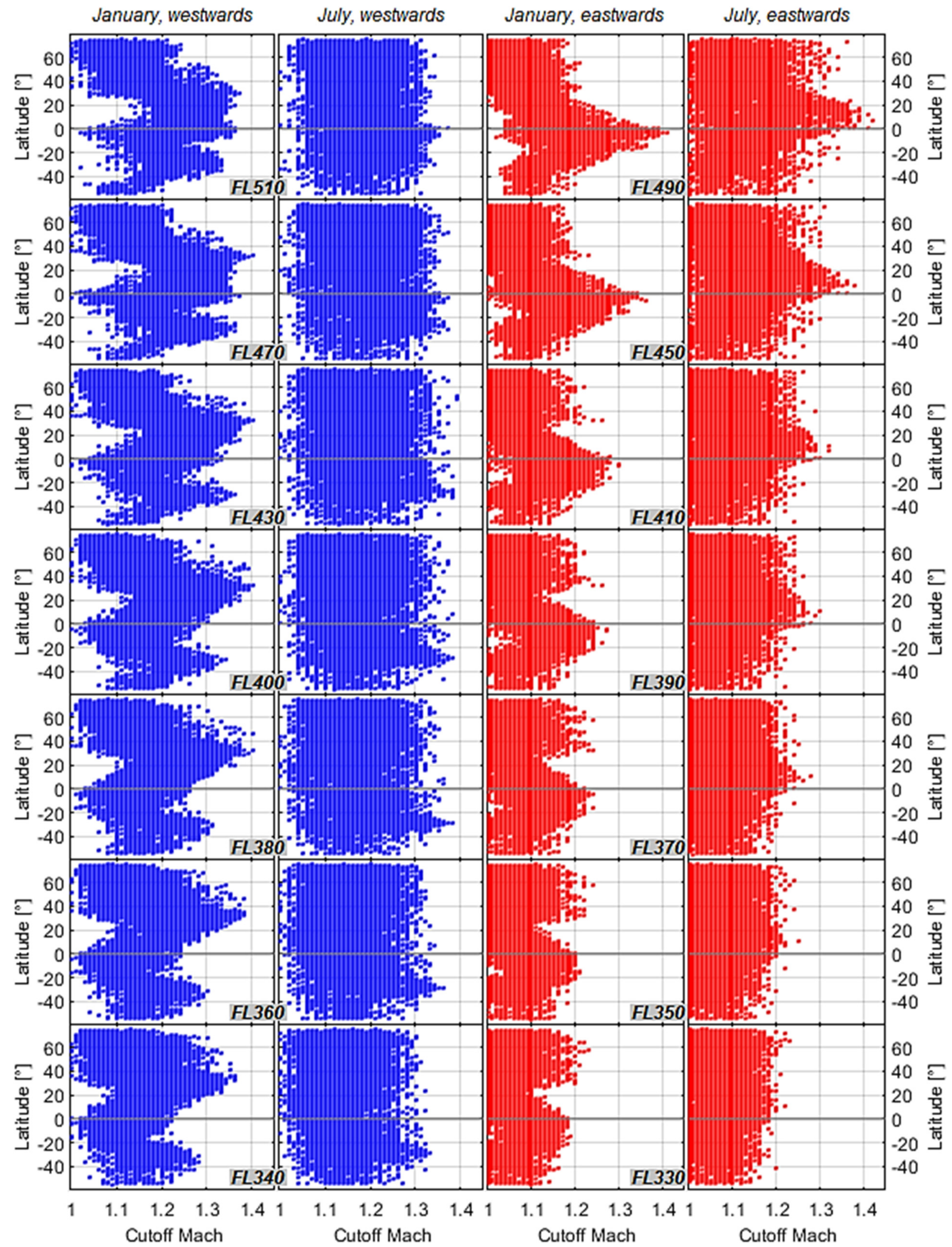

American Institute of Aeronautics and Astronautics 


\section{Flight times of different cruise modes for the $\mathrm{S} 4$ supersonic airliner in a calendar year's course}

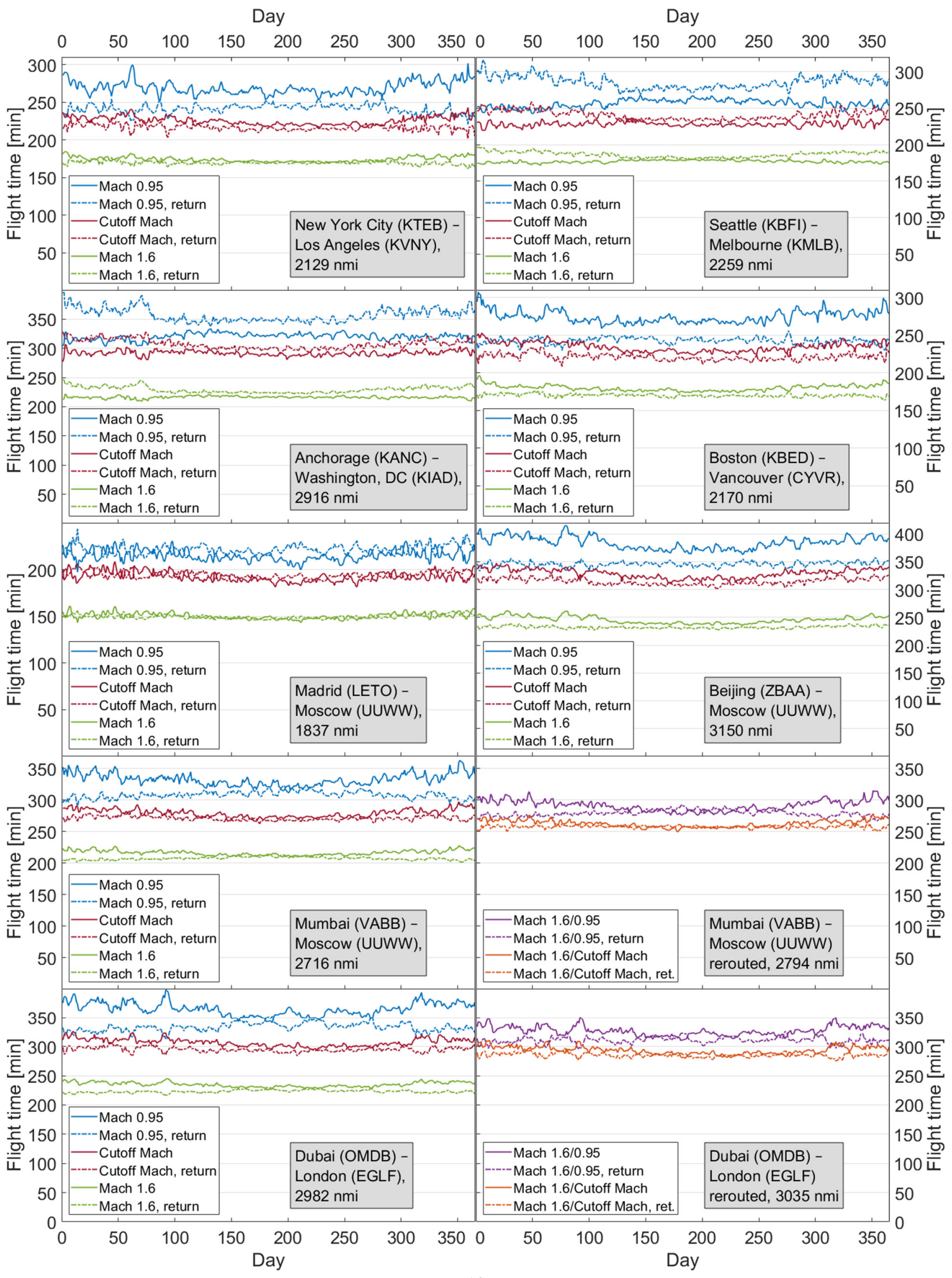

American Institute of Aeronautics and Astronautics 


\section{Acknowledgments}

The authors would like to express their gratitude to the Japanese Aerospace Agency (JAXA) and particularly to Atsushi Ueno and Hiroaki Ishikawa for their approval to use the comprehensive and meticulous set of flight performance data of their low-boom supersonic airliner design S4 (iteration 1.3.4, [7]). This was extremely helpful because such a sophisticated and reliable dataset requires multi-disciplinary expertise as well as considerable R\&D efforts and thus, is very hard to come by.

\section{References}

[1] Maglieri, D. J., Bobbitt, P. J., Plotkin, K. J., Shepherd, K. P., Coen, P. G., and Richwine, D. M., Sonic Boom: Six Decades of Research, National Aeronautics and Space Administration (NASA), Langley, VA, 2014.

[2] Nicholls, J. M., “A Note on the Calculation of 'Cut-off' Mach number,” Meteorological Magazine; Vol. 100, 1973, pp. 33-45.

[3] Plotkin, K., Matisheck, J., and Tracy, R., "Sonic Boom Cutoff Across the United States," 14th AIAAACEAS Aeroacoustics Conference, Vancouver, BC, 2008.

[4] Liebhardt, B., Linke, F., and Dahlmann, K., "Supersonic Deviations: Assessment of Sonic-Boom-Restricted Flight Routing," Journal of Aircraft; Vol. 51, No. 6, 2014, pp. 1987-1996. doi: 10.2514/1.C032591.

[5] Liebhardt, Bernd, Lütjens, Klaus, Swaid, Majed, Müller, Matthes N., and Ladewich, Maik, "Sonic Boom Carpet Computation as a Basis for Supersonic Flight Routing," AIAA Aviation Forum, Dallas, TX, 2019.

[6] Onyeonwu, R. O., The Effects of Wind and Temperature Gradients on Sonic Boom Corridors, Univ. Inst. for Aerospace Studies, Toronto, ON, 1971.

[7] Liebhardt, B., Lütjens, K., Ueno, A., and Ishikawa, H., "JAXA's S4 Supersonic Low-Boom Airliner - A Collaborative Study on Aircraft Design, Sonic Boom Simulation, and Market Prospects," AIAA Aviation Forum 2020, Virtual Event, 2020.

[8] Saint Martin, P. de, Stoufflet, B., Deremaux, Y., and Négrier, J., "Design of a Small Supersonic Transport Aircraft with High Environmental Constraints," International Council of Aerospace Sciences (ICAS), Anchorage, AK, 2008.

[9] Linke, F., Ökologische Analyse operationeller Lufttransportkonzepte (Environmental Analysis of Operational Air Transportation Concepts), Dissertation, Hamburg Technical University, Hamburg, 2016.

[10] Cliatt, L. J., Hill, M. A., and Haering, E. A., "Mach Cutoff Analysis and Results from NASA's Farfield Investigation of No-boom Thresholds," 22nd AIAA/CEAS Aeroacoustics Conference, American Institute of Aeronautics and Astronautics, Reston, VA, 2016. 